\title{
The effects of threatened abortions on pregnancy outcomes
}

\author{
Ahkam Göksel Kanmaz' , Abdurrahman Hamdi İnan², Emrah Beyan ${ }^{1}$, Adnan Budak \\ ${ }^{1}$ Izmir Tepecik Teaching and Research Hospital, Department of Obstetrics and Gynecology, Izmir, Turkey \\ ${ }^{2}$ Izmir Provincial Health Directorate, Izmir, Turkey
}

\begin{abstract}
Objectives: The effects of first trimester threatened abortions on prenatal and postnatal pregnancy outcomes.

Material and methods: Data from 24.835 pregnant women were retrospectively analysed. The pregnant women were divided into two groups according to whether they had a first trimester threatened abortion or not. The demographic data and prenatal, postnatal and labour outcomes were compared for the two groups. Those cases with miscarriages during their follow-up, pregnant women with systemic diseases, multiple pregnancies and patients who were diagnosed with cervical erosion and cervical polypoid formation during vaginal bleeding examinations were all excluded.

Results: The age $(p<0.001)$, ART pregnancy rate $(p=0.03)$ and nulliparity rate $(p=0.013)$ in those with the risk of miscarriage were statistically significantly higher than those without the risk. The gestational weeks $(p<0.001)$ and birth weights $(p<0.001)$ were significantly lower for the miscarriage group than in the control group. Hyperemesis gravidarum $(p<0.001)$, gestational diabetes mellitus (GDM) $(p<0.001)$ and placenta previa $(p=0.018)$ rates were statistically significantly and more frequent in the pregnancies with the threatened abortion group than in the control group. The rates of caesarean delivery were statistically significantly higher in the threatened abortion group $(p<0.001)$.

Conclusions: Threatened abortion between 6- and 14-weeks gestational age is a complication that may cause anxiety in the early weeks of pregnancy. But the treatment, follow-up and cause of threatened abortion all remain unclear.
\end{abstract}

Key words: abortion; pregnancy outcomes; treatment; first trimester

Ginekologia Polska 2019; 90, 4: 195-200

\section{INTRODUCTION}

The risk of miscarriage (threatened abortion) can be defined as either visible vaginal bleeding without cervical dilatation, or cervical dilation without vaginal bleeding in the early period of gestation.

Diagnosis is established when there is vaginal bleeding during speculum examination, a closed cervix and the presence of the fetal heart beat during ultrasonographic (USG) examinations [1]. Approximately $15-20 \%$ of all pregnancies have the risk of miscarriage [2]. Abortion occurs in approximately $50 \%$ of those pregnancies pre-diagnosed with the risk of miscarriage; however, it is predicted that $85-95 \%$ of pregnancies will possibly continue until the 24 th gestational week if cardiac activity is detected by ultrasonography [3,4].

As Lykke et al. [5] pointed out in 2010, several endometrial local factors such as local formation of thrombin, soluble fms-like tyrosine kinase-1, the down-regulation of both the epithelial E receptor-a and the progesterone receptor, and systemic factors such as progesterone and growth factors play a role in the continuation of pregnancy, from implantation to birth. Endocrine and inflammatory processes, particularly those derived from the endometrium, and attachment of the embryo to the endometrial surface play significant roles in the smooth progress of ongoing pregnancies [6]. Problems in these processes may first lead to placental invasion problems, followed by haemorrhages in the first trimester, and thus the risk of miscarriage or an actual miscarriage.

Pregnancy complications such as preeclampsia, intrauterine growth retardation (IUGR), low birth weight (LBW) and abruptio placentae are associated with placental problems; hence, the risk of these complications increases in the later weeks of pregnancies with the risk of miscarriage [7-11].

In our study, we aimed to examine the pregnancy outcomes of the women with and without threatened abortion 
who were treated at our clinic in order to, by comparison, identify the effects of threatened abortion on both prenatal and postnatal pregnancy outcomes.

\section{MATERIAL AND METHODS}

Our study was a retrospective review of the prenatal and postnatal outcomes of pregnancies that were examined, followed up, and delivered by physicians of Tepecik Education and Research Hospital Obstetrics and Gynecology Clinic between January 2013 and January 2015. The study commenced following the approval of the Tepecik Training and Research Hospital Ethics Committee (Reference number: 2017-9-1). The pregnant women in our study population were divided into 2 groups: those with the risk of miscarriage and those without the risk of miscarriage during the first trimester of pregnancy. The two groups were compared on the basis of body mass index (BMI), pregnancies after assisted reproductive techniques (ART pregnancies), placental pathologies (placenta previa, abruptio placentae), preeclampsia, gestational diabetes mellitus (GDM), hyperemesis gravidarum, low birth weight (LBW), pregnancy complications (such as preterm birth, birth shape), and neonatal complications (such as newborn intensive care need and stillbirth). Cases with complete or incomplete miscarriages during the follow-up period, those with no fetal heartbeat in the USG, and pregnant women with systemic diseases or multiple pregnancies were all excluded from the study. Although included in the study at the beginning, those patients who were diagnosed with cervical erosion and cervical polypoid formation during their vaginal bleeding examination were subsequently excluded from the study.

The risk of miscarriage was defined as a pregnancy with visible vaginal bleeding but no cervical dilatation and with fetal heartbeats in the USG. Gestational age was determined according to the latest menstrual history or by the first trimester crown-rump length measurements. The pregnancies that had a duration of less than 20 weeks or resulted in births $<500 \mathrm{~g}$ were accepted as nulliparous. The results of the pregnancies were retrospectively collected from the hospital information system, and the delivery room, newborn care room and intensive care registries. Our clinic uses the criteria of ACOG 2013 [12] for the diagnosis of preeclampsia and ADA criteria $[13,14]$ for the diagnosis of gestational diabetes mellitus (GDM). Infants born $<2.5 \mathrm{~kg}$ were defined as LBW, and those born $>4 \mathrm{~kg}$ were diagnosed with macrosomia.

The pregnancies that resulted in births before the 37th week of gestational age were defined as preterm pregnancies, and the infants born without a heartbeat after the 20th gestational week were accepted as stillbirths. The pregnancies with persistent nausea and vomiting accompanied by ketone positivity and $5 \%$ weight loss in the first trimester were accepted as hyperemesis gravidarum.

\section{Statistical Analysis}

The results are presented as frequencies and percentages. Normality tests appropriate to the number of pregnancies in this study were chosen, and normal distribution was accepted at a value of $p>0.05$. Data with normal distribution were presented as mean \pm SD and data without normal distribution were presented as median ( $\mathrm{min}-\mathrm{max}$ ). An independent sample t-test was used for parametric distributions, and the Mann-Whitney U-test was used for non-parametric distributions. The Chi-square test was used for categorical variables between groups. Logistic regression models were performed for the complications statistically determined to be associated with first trimester haemorrhage, and the results were presented as odds ratio (OR) $(95 \% \mathrm{Cl})$. P-values $<0.05$ were considered significant. Statistical analyses were performed using SPSS 22.0 for Windows.

\section{RESULTS}

Overall, 24.838 pregnant women who were admitted to our hospital between January 2013 and January 2015 were retrospectively screened. 2.180 pregnancies were diagnosed as a threatened abortion with ICD 10 code but only 1.626 of those pregnancies were included in the study group. 554 out of the original 2.180 pregnancies with the risk of miscarriage did not meet the inclusion criteria. Only 19.434 pregnancies were included in the control group because 3.224 pregnancies in the control group did not meet the inclusion criteria.

The demographic data of the pregnancies are summarised in Table 1. The age $(p<0.001)$ and ART pregnancy rates $(p=0.03)$ in those with the risk of miscarriage were statistically significantly higher than those without the risk. Both the gestational weeks $(p<0.001)$ and birth weights ( $p<0.001$ ) of the pregnancies with the risk of miscarriage were significantly lower than the control group. The nulliparity rate of the pregnancies with the risk of miscarriage ( $p=0.013$ ) was statistically significantly higher than those without the risk. There was no statistically significant difference between mean BMI values and genders of the babies in both groups.

Table 2 summarises gestation, birth and newborn outcomes of the pregnancies with and without the risk of miscarriage in the first trimester. Hyperemesis gravidarum was statistically significantly more frequent in the pregnancies with the risk of miscarriage than in those without the risk ( $p<0.001$ and OR: 3.42; 95\% Cl: 2.78-4.22). Similarly, GDM incidence was higher in the pregnancies with the risk of miscarriage than those without the risk $(\mathrm{p}<0.001$ and OR: $1.62 ; 95 \% \mathrm{Cl}: 1.35-1.93)$. There was no statistically significant difference in preeclampsia rates between pregnancies with the risk of miscarriage and those of the control group (OR: 0.94; 95\% Cl: 0.72-1.22). The incidence of placenta previa in pregnancies with a risk of miscarriage was significantly 
Table 1. Comparison of demographic data of first trimester threatened abortion non-first trimester miscarriage risk

\begin{tabular}{|l|l|l|l|}
\hline & Threatened Abortion $(\mathbf{n}, \mathbf{1 6 2 6})$ & Without Threatened Abortion $(\mathbf{n}, \mathbf{1 9 4 3 4})$ & P value \\
\hline Age (mean \pm SD) & $28.04 \pm 6.225$ & $27.46 \pm 6.185$ & $<0.001$ \\
\hline BMI (mean \pm SD) & $26.4 \pm 5.4$ & $26.3 \pm 5.3$ & 0.441 \\
\hline $\begin{array}{l}\text { Nulliparity }(n, \%) \\
\text { Multiparity }(n, \%)\end{array}$ & $\begin{array}{l}610(37.5 \%) \\
1016(62.5 \%)\end{array}$ & $6712(34.5 \%)$ & 0.013 \\
\hline Pregnancy after ART $(n, \%)$ & $86(5.3 \%)$ & $42723(65.5 \%)$ & 0.03 \\
\hline $\begin{array}{l}\text { Gestational week (median, min-max) } \\
\text { Birth weight (median, min-max) }\end{array}$ & $38(20-42)$ & $39(20-42)$ & $<0.001$ \\
\hline $\begin{array}{l}\text { Fetal sex }(n, \%) \\
\text { Boy } \\
\text { Girl }\end{array}$ & $3167(400-5450)$ & $3200(400-5750)$ & $<0.001$ \\
\hline
\end{tabular}

Table 2. Comparison of the results of the pregnancies with the risk of miscarriage and those without the risk

\begin{tabular}{|c|c|c|c|c|}
\hline & $\begin{array}{l}\text { With Threatened } \\
\text { Abortion }(n, 1626)\end{array}$ & $\begin{array}{l}\text { Without Threatened } \\
\text { Abortion }(n, 19434)\end{array}$ & P value & $\begin{array}{l}\text { Odds } \\
\text { Ratio }(95 \% \mathrm{Cl})\end{array}$ \\
\hline Hyperemesis gravidarum $(n, \%)$ & $106(6.5 \%)$ & $387(\% 2)$ & $<0.001$ & $3.42(2.78-4.22)$ \\
\hline Gestational diabetes $(n, \%)$ & $140(8.6 \%)$ & $1067(5.5 \%)$ & $<0.001$ & $1.62(1.35-1.93)$ \\
\hline Preeclampsia (n, \%) & $61(3.8 \%)$ & $770(4 \%)$ & 0.673 & $0.94(0.72-1.22)$ \\
\hline Placenta previa (n, \%) & $13(0.8 \%)$ & $77(0.4 \%)$ & 0.018 & $1.59(0.9-2.80)$ \\
\hline Abruptio placentae (n, \%) & $7(0.4 \%)$ & $60(0.3 \%)$ & 0.473 & $1.39(0.65-2.99)$ \\
\hline $\begin{array}{l}\text { Caesarean }(n, \%) \\
\text { Primary caesarean section }\end{array}$ & $\begin{array}{l}969(59.6 \%) \\
588(36.2 \%)\end{array}$ & $\begin{array}{l}10675(54.9 \%) \\
6069(31.2 \%)\end{array}$ & $\begin{array}{l}<0.001 \\
<0.001\end{array}$ & $\begin{array}{l}1.20(1.09-1.33) \\
1.17(1.02-1.33)\end{array}$ \\
\hline Non-vertex presentation $(n, \%)$ & $79(4.9 \%)$ & $815(4.2 \%)$ & 0.001 & $1.16(0.92-1.47)$ \\
\hline $\begin{array}{l}\text { Preterm birth ( } \mathrm{n}, \%) \\
\text { Extremely preterm (<28 weeks) } \\
\text { Very preterm ( } 28-32 \text { weeks) } \\
\text { Moderate preterm ( } 32-37 \text { weeks) }\end{array}$ & $\begin{array}{l}61(3.8 \%) \\
39(2.4 \%) \\
218(13.4 \%)\end{array}$ & $\begin{array}{l}263(1.4 \%) \\
341(1.8 \%) \\
2482(12.1 \%)\end{array}$ & $\begin{array}{l}<0.001 \\
0.07 \\
0.116\end{array}$ & $\begin{array}{l}2.84(2.14-3.77) \\
1.37(0.98-1.92) \\
1.05(0.91-1.22)\end{array}$ \\
\hline $\begin{array}{l}\text { LBW }(n, \%) \\
\text { Moderate low birth weight } \\
\text { Very low birth weight } \\
\text { Extremely low birth weight }\end{array}$ & $\begin{array}{l}160(9.8 \%) \\
36(2.2 \%) \\
61(3.7 \%)\end{array}$ & $\begin{array}{l}1693(8.7 \%) \\
286(1.4 \%) \\
300(1.5 \%)\end{array}$ & $\begin{array}{l}0.124 \\
0.007 \\
<0.001\end{array}$ & $\begin{array}{l}1.14(0.96-1.35) \\
1.51(1.06-2.15) \\
2.48(1.87-3.28)\end{array}$ \\
\hline Macrosomia $(n, \%)$ & $84(5.2 \%)$ & $1009(5.2 \%)$ & 0.967 & $0.99(0.79-1.24)$ \\
\hline Need for newborn intensive care $(n, \%)$ & $179(11 \%)$ & $1631(8.4 \%)$ & $<0.001$ & $1.34(1.15-1.58)$ \\
\hline Stillbirth (n, \%) & $32(2 \%)$ & $280(1.4 \%)$ & 0.083 & $1.37(0.9-1.96)$ \\
\hline
\end{tabular}

higher than in the control group ( $p=0.018$ and OR: 1.59; $95 \% \mathrm{Cl}: 0.90-2.80)$. There was no statistically significant difference in the frequency of placental detachment between pregnancies with the risk of miscarriage and those without the risk (OR 1.39; 95\% Cl: 0.65-2.99). In the group with first trimester miscarriage risk, the rates of caesarean delivery, the frequency of non-vertex head presentation delivery, and the number of primary caesarean sections were statistically significantly higher than those without threatened abortion ( $p<0.001$ and OR: 1.20; 95\% Cl: 1.09-1.33; $p=0.001$ and OR: $1.16 ; 95 \% \mathrm{Cl}: 0.92-1.47 ; \mathrm{p}<0.001$ and $\mathrm{OR}: 1.17 ; 95 \%$ $\mathrm{Cl}$ : $1.02-1.33$, respectively). Extremely preterm and very preterm incidence in the pregnancies with the risk of miscarriage were statistically higher than the control group
( $p<0.001$ and OR: $2.84 ; 95 \% \mathrm{Cl}: 2.14-3.77$ and $\mathrm{p}=0.07$ and OR: $1.37 ; 95 \% \mathrm{Cl}$ : 0.98-1.92). Similarly, extremely low birth weight and very low birth weight rates were significantly higher in the pregnancies with the risk of miscarriage than in the control group ( $p<0.001$ and OR: $2.48 ; 95 \% \mathrm{Cl}$ : $1.87-3.28$ and $p=0.007$ and OR $1.51 ; 95 \% \mathrm{Cl}: 1.06-2.15)$. Newborn intensive care needs were higher for infants born after pregnancies with threatened abortion during the first trimester than those for infants born to the control group ( $p<0.001$ and OR: 1.34; 95\% Cl: 1.15-1.58). Moderate LBV, moderate preterm gestation, stillbirth and macrosomic infantile incidence rates were similar in the pregnancies of both the risk of miscarriage group and the control group (Tab. 2). 


\section{DISCUSSION}

Although pregnancies with the risk of miscarriage in the first trimester constitute approximately $15-20 \%$ of all pregnancies, there is insufficient information in the literature about the complications that may occur during the post-diagnosis gestational weeks of these pregnancies [2]. The purpose of our study was to investigate the relationship between the risk of miscarriage and other pregnancy complications in the first trimester of pregnancy.

In our study, consistent with the literature, the mean age of pregnancies with the risk of miscarriage was significantly higher than in the control group [11, 15]. Nulliparity and ART pregnancy rates in pregnancies with the risk of miscarriage were higher than in the control group. Similar to our study, there are studies showing that in ART pregnancies, the risk of miscarriage is higher than in spontaneous pregnancies [16]. The relationship between parity and the risk of miscarriage is contradictory in the literature $[11,15,17]$. We think that the differences in those results are due to differences in geographical and cultural conditions and the different criteria used by various researchers in control group selection. The mean gestational age and mean birth weight in pregnancies with the risk of miscarriage in the first trimester were lower than those in pregnancies without the risk of miscarriage. Since previous publications show that there is a relationship between the risk of miscarriage and preterm delivery, it would not be wrong to expect that the average gestational week and average birth weight would be lower than pregnancies without the risk of miscarriage $[9,11,15$, 18-20]. There was no significant difference between the groups in terms of fetal sex and BMI (Tab. 1).

In our study, among the pregnancies with the risk of miscarriage in the first trimester, the incidence of accompanying hyperemesis gravidarum in the first trimester was higher than in the control group (OR: 3.42). Since there is not enough evidence in the literature regarding the incidence of hyperemesis gravidarum in pregnancies with the risk of miscarriage in the first trimester, it was not possible to compare our results with other findings. Previous studies have shown a relationship between hyperemesis gravidarum and inflammation during pregnancy [19, 21, 22]. Therefore, as a result of inflammation that may occur in pregnancy in the first trimester, hyperemesis gravidarum can be expected in the pregnancies with the risk of miscarriage. Like the study by Evrenos et al. in 2014, we found the incidence of GDM higher in pregnancies with threatened abortion than in those without the risk [23].

Weiss et al. have shown that there may be an increase in the incidence of preeclampsia, which is a serious complication, in pregnancies with the risk of miscarriage [11]. Conversely, in our study, and in many instances in the literature there was no relationship between preeclampsia and the risk of miscarriage $[7,9,19,23]$. In our study, placenta previa was more frequent in the patients with the risk of miscarriage in the first trimester than in the control group. Placenta previa and the risk of miscarriage were found to be inter-related in our results, and this result is like other results found in the literature [11, 18, 19, 24].

However, contrary to our results, there are publications that do not establish a relationship between placenta previa and the risk of miscarriage $[23,25]$. Although we detected abruptio placentae more frequently in the group of patients with the risk of miscarriage than in the control group (OR 95\% Cl 2.99), no significant difference was detected. Our abruptio placenta results are like many previous studies $[9,11,18,23,24]$. However, there are also publications linking abruptio placentae with the risk of miscarriage [19].

Our study has demonstrated that there is an increase in the frequency of caesarean section, especially the frequency of primary caesarean section, in those pregnancies with the risk of miscarriage in the first trimester. Our results are supported by some of the literature [11, 23, 24]. However, there are also publications that report no change in caesarean frequency in pregnancies with the risk of miscarriage $[19,25]$. Like the study by Evrenos et al., we found that malpresentation frequency was higher in pregnancies with the risk of miscarriage than those without the risk [23].

In our study, and consistent with the literature, among the pregnancies with the risk of miscarriage, the rate of births before the $28^{\text {th }}$ week and between the $28^{\text {th }}$ and $32^{\text {nd }}$ weeks was higher than in the control group $[9,11,15,19$, $23,25]$. Our study showed a moderate preterm birth rate of between 34 and 37 weeks which was similar in both the study and control groups. In a study conducted by Wijesiriwardana et al. [24], the preterm births were reported as occurring before or after 34 weeks, and both groups of preterm births were more frequent in the pregnancies with the risk of miscarriage than those without the risk. In our study, the incidence of extremely LBW and very LBW were significantly higher in pregnancies with the risk of miscarriage in the first trimester than in the control group, and this finding is similar to our preterm delivery results. Several studies in the literature show similar results in terms of $\operatorname{LBW}[9,18,19,25]$. Like the preterm pregnancy results, there was no difference between the study and control groups in terms of moderate LBW ratios. Mulik et al. [18] subdivided LBW and found that moderate LBW ratios were higher in pregnancies with the risk of miscarriage. However, Dadkhah et al. contrary to other literature, reported that the rates for small for gestational age (SGA) pregnancies did not differ between the group with the risk of miscarriage and the group without the risk. [7]. In our study, the fact that only moderate preterm birth and moderate LBW ratio differences were not significant between groups can be explained by the fact that our hospital 
is a tertiary hub that receives many referrals. Especially, since we are the reference hospital for western Turkey, preterm pregnancies are common in our hospital and our results may differ from results in other literature.

In our study, the incidence of macrosomic fetus and stillbirth in pregnancies with the risk of miscarriage did not differ from the control group. There are different conclusions in the literature on the incidence of stillbirths in pregnancies with a first trimester miscarriage risk. In addition to the publications that support our results $[15,16,18]$, there are also publications that have detected a significant relationship between stillbirth frequency and the risk of miscarriage $[19,23,24]$. The babies born after the pregnancies with first trimester bleeding in the study required more infant intensive care than those in the control group $(p<0.001)$. Since the complications, such as preterm delivery and LBW, which will directly affect the baby, are more common in pregnancies with the risk of miscarriage, it is reasonable to expect an increase in the need for newborn intensive care in the pregnancies with the risk of miscarriage. In similar studies in the literature, the newborn intensive care need was more common in pregnancies with the risk of miscarriage than among those without the risk, as was the case in our study $[19,24]$. A pregnancy with the risk of miscarriage is a complication that may occur in 1 out of 5 pregnant women and cause anxiety in pregnant women and their families [2]. There is still no definitive information on the complications that pregnant women with first trimester threatened abortion might encounter in the later weeks of gestation. Our study can contribute to the literature at this point. Our study is one of the rare studies in the literature that is single-centred, with a high number of patients and that compares pregnancy complications between a study group comprised of women with the risk of miscarriage in the first trimester with a control group without the miscarriage risk. Although the retrospective nature of our study can be regarded as a limitation, as is the case in similar studies in the literature, we believe that this limitation has been overcome by our strict patient selection criteria. In conclusion, treatment, follow-up and the cause of threatened abortion in the first trimester remain unclear, and the miscarriage risk is a complication that may cause anxiety in the early weeks of the pregnancy.

We believe that multi-centred, randomised, controlled studies on the risk of miscarriage will help both pregnant women and physicians to be more knowledgeable about this complication.

\section{Contributors' statements}

AGK conceived, designed and did statistical analysis and editing of the manuscript.

$\mathrm{AHI}$ did data collection and manuscript writing.
$E B$ and $A B$ reviewed and gave final approval of the manuscript.

\section{Conflicts of interest}

The authors declare that they have no conflicts to interest relevant to this article.

\section{REFERENCES}

1. Woodward PJ, Kennedy A, Sohaey R. Diagnostic imaging: Obstetrics.

2. Farrell T, Owen P. The significance of extrachorionic membrane separation in threatened miscarriage. BJOG: An International Journal of Obstetrics and Gynaecology. 1996; 103(9): 926-928, doi: 10.1111/j.14710528.1996.tb09915.x.

3. Chung T, Sahota DS, Lau TK, et al. Threatened Abortion: Prediction of Viability Based on Signs and Symptoms. The Australian and New Zealand Journal of Obstetrics and Gynaecology. 1999; 39(4): 443-447, doi: 10.1111/j.1479-828x.1999.tb03129.x.

4. Mouri MI, Rupp TJ. Threatened Abortion. StatPearls Publishing. 2018.

5. Lykke JA, Dideriksen KL, Lidegaard O, et al. First-trimester vaginal bleeding and complications later in pregnancy. Obstet Gynecol. 2010; 115(5): $935-$ 944, doi: 10.1097/AOG.0b013e3181da8d38, indexed in Pubmed: 20410766.

6. Schatz F, Guzeloglu-Kayisli O, Arlier S, et al.The role of decidual cells in uterine hemostasis, menstruation, inflammation, adverse pregnancy outcomes and abnormal uterine bleeding. Hum Reprod Update. 2016; 22(4): 497-515, doi: 10.1093/humupd/dmw004, indexed in Pubmed: 26912000.

7. Dadkhah F, Kashanian M, Eliasi G. A comparison between the pregnancy outcome in women both with or without threatened abortion. Early Hum Dev. 2010; 86(3): 193-196, doi: 10.1016/j.earlhumdev.2010.02.005, indexed in Pubmed: 20231080.

8. Parrish L, Muglia L, DeFranco E. Bleeding during pregnancy is associated with familial preterm birth. The Journal of Maternal-Fetal \& Neonatal Medicine. 2017; 32(1): 73-79, doi: 10.1080/14767058.2017.1371693.

9. Ozdemirci S, Karahanoglu E, Esinler D, et al. Influence of threatened miscarriage on pregnancy and early postpartum period: a case-control report. The Journal of Maternal-Fetal \& Neonatal Medicine. 2014; 28(10): 1186-1189, doi: 10.3109/14767058.2014.947577.

10. Das AG, Gopalan S, Dhahwal LK. Fetal Growth and Perinatal Outcome of Pregnancies Continuing After Threatened Abortion. The Australian and New Zealand Journal of Obstetrics and Gynaecology. 1996; 36(2): 135-139, doi: 10.1111/j.1479-828x.1996.tb03269.x.

11. Weiss J, Malone F, Vidaver J, et al. Threatened abortion: a risk factor for poor pregnancy outcome, a population-based screening study. American Journal of Obstetrics and Gynecology. 2004; 190(3): 745-750, doi: 10.1016/j.ajog.2003.09.023.

12. American College of Obstetricians and Gynecologists, Task Force on Hypertension in Pregnancy. Hypertension in pregnancy. Report of the American College of Obstetricians and Gynecologists' Task Force on Hypertension in Pregnancy. Obstet Gynecol. 2013; 122(5): 1122-1131, doi: 10.1097/01.AOG.0000437382.03963.88, indexed in Pubmed: 24150027.

13. American Diabetes Association. Diagnosis and classification of diabetes mellitus. Diabetes Care. 2014; 37 Suppl 1: S81-S90, doi: 10.2337/dc14-S081, indexed in Pubmed: 24357215.

14. American Diabetes Association . Diagnosis and Classification of Diabetes Mellitus. Diabetes Care. 2012; 35(Supplement 1): S64-S71, doi: 10.2337/dc12-s064.

15. Yakıştıran B, Yüce T, Söylemez F. First Trimester Bleeding and Pregnancy Outcomes: Case-Control Study. International Journal of Women's Health and Reproduction Sciences. 2015; 4(1): 4-7, doi: 10.15296/ijwhr.2016.02.

16. De Sutter $P$, Bontinck J, Schutysers V, et al. First-trimester bleeding and pregnancy outcome in singletons after assisted reproduction. Hum Reprod. 2006; 21(7): 1907-1911, doi: 10.1093/humrep/del054, indexed in Pubmed: 16501033.

17. Özdemirci Ş, Demirdağ E, Kasapoğlu T, et al. Obstetric outcome of second trimester antenatal bleeding. J Matern Fetal Neonatal Med. 2016; 29(20):3395-3399, doi: 10.3109/14767058.2015.1130815, indexed in Pubmed: 26692339.

18. Mulik V, Bethel J, Bhal K. A retrospective population-based study of primigravid women on the potential effect of threatened miscarriage on obstetric outcome. Journal of Obstetrics and Gynaecology. 2009; 24(3): 249-253, doi: 10.1080/01443610410001660724. 
19. Saraswat $L$, Bhattacharya $S$, Maheshwari A, et al. Maternal and perinatal outcome in women with threatened miscarriage in the first trimester: a systematic review. BJOG. 2010; 117(3): 245-257, doi: 10.1111/j.14710528.2009.02427.x, indexed in Pubmed: 19943827.

20. Bhattacharya S, Townend J, Shetty A, et al. Does miscarriage in an initial pregnancy lead to adverse obstetric and perinatal outcomes in the next continuing pregnancy? BJOG. 2008; 115(13): 1623-1629, doi: 10.1111/j 1471-0528.2008.01943.x, indexed in Pubmed: 18947339.

21. Tayfur C, Burcu DC, Gulten O, et al. Association between platelet to lymphocyte ratio, plateletcrit and the presence and severity of hyperemesis gravidarum. J Obstet Gynaecol Res. 2017; 43(3): 498-504, doi: 10.1111/jog.13228, indexed in Pubmed: 28160526.
22. Kurt R, Güler A, Silfeler $D$, et al. Relation of inflammatory markers with both presence and severity of hyperemesis gravidarum. Polish Gynaecology. 2014; 85(8), doi: 10.17772/gp/1776.

23. Evrenos AN, Cakir Gungor AN, Gulerman C, et al. Obstetric outcomes of patients with abortus imminens in the first trimester. Arch Gynecol Obstet. 2014; 289(3): 499-504, doi: 10.1007/s00404-013-2979-5, indexed in Pubmed: 23912531.

24. Wijesiriwardana A, Bhattacharya S, Shetty A, et al. Obstetric outcome in women with threatened miscarriage in the first trimester. Obstet Gynecol. 2006; 107(3): 557-562, doi: 10.1097/01.AOG.0000199952.82151. de, indexed in Pubmed: 16507924.

25. Davari-Tanha F, Shariat M, Kaveh M, et al. Acta medica Iranica. 2008; 46(4). 